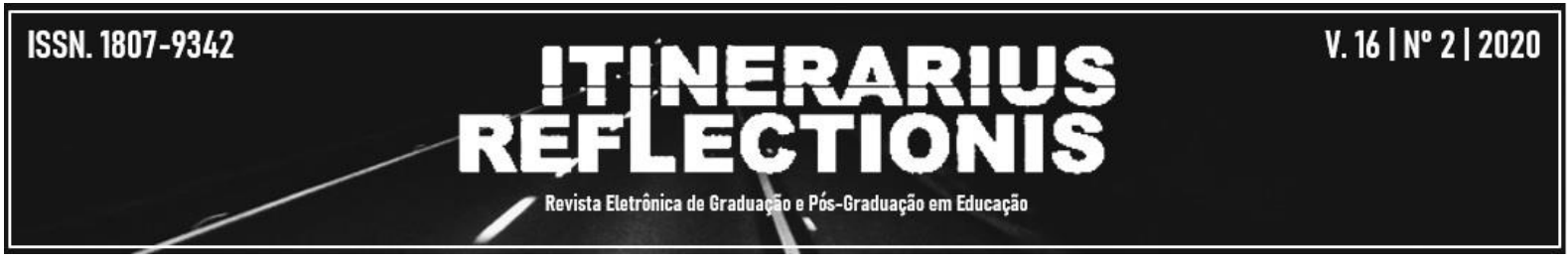

\title{
CASOS DE ENSINO NA FORMAÇÃO PROFESSORES: contribuições para a reflexão sobre a prática docente
}

\section{Viviane Preichardt Duek ${ }^{1}$}

Resumo: Este estudo teve como objetivo analisar o potencial dos casos de ensino na promoção de processos reflexivos de professoras que atuam com alunos com deficiência nos anos iniciais do ensino fundamental. Trata-se de uma pesquisa-intervenção desenvolvida em uma escola da rede pública municipal de Natal/RN, que contou com a participação de oito professoras. Metodologicamente, adotou-se o modelo construtivo-colaborativo, tendo os casos de ensino como principal estratégia formativa e investigativa. Os resultados indicam que a elaboração dos casos de ensino pelas professoras fomentou processos reflexivos, entendidos como relevantes para a aprendizagem e o desenvolvimento profissional docente. Ao possibilitar que práticas fossem descritas, tal estratégia assumiu importante papel na sistematização dos conhecimentos e das teorias pessoais que embasam a ação pedagógica, além de permitir o compartilhamento de informações e discussão de experiências de ensino entre os pares, vislumbrando o redimensionamento de suas práticas. Conclui-se, assim, que os casos de ensino proporcionaram às professoras oportunidades para aprender e desenvolverem-se profissionalmente, sugerindo a sua adequação como ferramenta a ser utilizada em pesquisas e em ações de formação continuada, ancorados na perspectiva do professor reflexivo.

Palavras-chave: Formação reflexiva. Casos de ensino. Educação inclusiva.

\section{TEACHING CASES ON TEACHERS' FORMATION: contributions to reflecting upon teaching practice}

\begin{abstract}
The objective of this study is to analyze the potential of teaching cases in the promotion of reflexive processes of teachers who work with students with disabilities in the initial years of elementary school. It is a research-intervention developed in a public school of Natal/RN, with the participation of eight teachers. The methodology adopted is a constructive-collaborative model, with teaching cases being the main strategy for formation and investigation. The results indicate that the elaboration of teaching cases by the teachers fostered reflexive processes, considered relevant for teachers learning and professional development. By describing the practice, such strategy becomes a relevant role in systematizing the knowledge and personal theories that support pedagogical practice, allowing information sharing as well as promoting debates upon teaching experiences among peers, aiming the reassessment of their practices. It was concluded that teaching cases provided teachers with learning opportunities and professional development, indicating its appropriateness as a tool for researches and in continued teachers' formation activities, supported by the reflexive teacher perspective.
\end{abstract}

Key-words: Reflexive formation. Teaching cases. Inclusive education.

\footnotetext{
${ }^{1}$ Doutora em Educação pela Universidade Federal do Rio Grande do Norte (UFRN) e Mestre em Educação pela Universidade Federal de Santa Maria (UFSM). Professora Adjunta na Universidade do Estado de Santa Catarina (UDESC), vinculada ao Centro de Ciências da Saúde e do Esporte. Membro do Laboratório de Pesquisa em Práticas Pedagógicas da Educação Física (LAPRAPEF). E-mail: vividuek@ hotmail.com.
} 


\section{INTRODUÇÃO}

A inclusão de pessoas com deficiência no ensino regular tem sido temática recorrente nas discussões do campo educacional. Isso vem contribuindo, segundo Vargas (2006), para a incorporação, por parte das escolas, de um discurso que prevê uma ação pedagógica voltada às diferenças. Entretanto, receber esses estudantes e garantir a sua permanência no ambiente escolar ainda representa um enorme desafio para muitas instituições da Educação Básica e para os professores que nelas atuam.

Neste sentido, evidencia-se a necessidade de investimento em ações de formação continuada mais afinadas com a realidade escolar, possibilitando o aprimoramento das práticas pedagógicas desenvolvidas neste contexto. Visando atender a esse propósito, foi delineada uma pesquisa-intervenção que buscou contribuir para a investigação e a promoção de processos de aprendizagem e desenvolvimento profissional de professores que atuam com alunos com deficiência nos anos iniciais do ensino fundamental, por meio de casos de ensino. O estudo contou com a participação de oito professoras de uma escola da rede pública municipal de Natal/RN, que analisaram casos de ensino escritos por outras profissionais, além de elaborarem um caso de ensino a partir de situações vividas junto a alunos com deficiência em sua trajetória docente.

Enquanto recorte de um estudo maior, este artigo objetiva analisar o potencial dos casos de ensino na promoção de processos reflexivos de professoras que atuam com alunos com deficiência nos anos iniciais do ensino fundamental. Tem-se como pressuposto que os casos de ensino caracterizam-se enquanto uma ferramenta capaz de fomentar processos reflexivos, auxiliando os professores na construção e/ou reconstrução do conhecimento profissional da docência (MIZUKAMI, 2000). Em outras palavras, entende-se que a análise e a elaboração de casos de ensino quando realizada de forma sistemática, serve para desencadear a reflexão sobre a prática pedagógica em contextos de formação inicial e continuada.

Portanto, este texto está estruturado da seguinte forma: em um primeiro momento, são apresentados alguns aportes teóricos sobre a formação de professores e também sobre as possibilidades da estratégia de casos de ensino fomentar processos de reflexão docente. Em seguida, faz-se uma breve descrição dos aspectos metodológicos do estudo, explicitando o uso dos casos de ensino no contexto desta pesquisa. Por fim, são apresentados e analisados dados que permitem descrever os processos de reflexão docente a partir da elaboração dos casos de 
ensino, destacando as possíveis contribuições desta estratégia para a formação docente com vistas ao desenvolvimento de uma prática educacional inclusiva.

\section{FORMAÇÃO REFLEXIVA DE PROFESSORES E CASOS DE ENSINO}

As diversas mudanças sofridas pela escola contemporânea vêm projetando novas demandas sobre o trabalho docente, extrapolando a relação linear entre ensino e aprendizagem na qual ao professor cabe unicamente ensinar e, ao aluno, aprender. Crescem, assim, as exigências acerca de um novo perfil de profissional do ensino, que tenha pleno domínio do conteúdo que ensina e de como proceder de forma eficiente (MIZUKAMI et. al., 2002), a fim de atender às singularidades de uma clientela escolar cada vez mais diversa, seja cognitiva, social, cultural, étnica ou linguisticamente.

Com efeito, ensinar caracteriza-se como uma atividade complexa, contextual e imprevisível, na qual o professor é convocado a analisar situações e tomar decisões para os problemas que surgem no cotidiano escolar. Em face desta complexidade e especificidade da prática docente, a abordagem reflexiva na formação inicial e continuada de professores tem chamado a atenção para o debate em torno de modelos de formação profissional, considerados insuficientes para uma análise mais coerente dos processos de ensinar e aprender (ZEICHNER, 1993; ALARCÃO, 1996; 2002; 2004; MIZUKAMI, 2000; 2002; PERRENOUD, 2002; SANTOS, 2008; dentre outros). Na ótica desses autores, fomentar a experiência reflexiva nos processos de formação docente é de suma relevância para o reexame das crenças subjacentes às decisões pedagógicas desses profissionais e para a análise dos conhecimentos profissionais, assim como para problematizar as finalidades e a validade das situações educacionais por eles organizadas.

Entendida como elemento de aprendizagem e de desenvolvimento profissional, a reflexão é apontada por Mizukami et. al. (2002, p. 16) como o fio condutor do processo formativo, na medida em que vai "“[...] produzindo os sentidos e explicitando os significados ao longo de toda a vida do professor, garantindo, ao mesmo tempo, os nexos entre a formação inicial, a continuada e as experiências vividas". Desta forma, a reflexão surge como o elemento que possibilita ao professor fazer as conexões entre os diferentes tipos de conhecimentos que ele possui, advindos dos diversos momentos da sua configuração profissional, abrangendo desde a sua experiência como discente, passando pela sua experiência docente, até a sua formação continuada. 
Um dos primeiros estudos publicados no sentido de compreender o professor como um profissional reflexivo foi produzido por Donald A. Schön ${ }^{2}$, difundindo e expandindo o conceito de reflexão no meio educacional. $\mathrm{O}$ modelo da racionalidade prática, proposto por Schön, concebe que o professor, em seu contexto de trabalho, é constantemente confrontado com situações singulares e incertas que precisam ser investigadas e compreendidas. Sob essa ótica, defende que a formação do profissional inclua um forte componente de reflexão a partir dos problemas concretos conferidos pela prática, pois somente por essa via um profissional é capaz de aprender e de tomar as decisões apropriadas frente às zonas de indeterminação das situações reais (ALARCÃO, 1996).

Formar o professor na perspectiva proposta por Schön (2000) implica considerar três tipos de reflexão por ele definidos: reflexão na ação (o pensar sobre o que faz no mesmo tempo em que está atuando), reflexão sobre a ação (reconstrói a ação mentalmente para analisá-la retrospectivamente) e a reflexão sobre a reflexão na ação (reflexão crítica após realizar a ação). Deste modo, o profissional reflexivo, para Schön, é aquele que permite ser surpreendido pelas situações escolares que vivencia e ficar confuso diante delas. Mais que isso, procura analisar os motivos que o levaram à surpresa e à confusão, buscando resolver a situação que o intrigou, seja atuando no momento em que a situação ocorre, seja atuando posteriormente, depois de ter refletido sobre a ação e sobre a reflexão na ação.

O paradigma do professor reflexivo inaugura novas perspectivas no campo da formação, em contraposição às correntes que circunscrevem o professor como um técnico, apenas, e a prática pedagógica como um espaço de ajustamento dos conhecimentos oriundos da ciência aplicada. Por conseguinte, impõe-se a necessidade de reformulação das bases da formação profissional, apostando na capacidade do professor em analisar situações vivenciadas no cotidiano escolar, de modo a intervir sobre elas.

Embora seus estudos não tenham, originalmente, se referido ao professor, as ideias de Schön têm se mostrado pertinentes para reexaminar o trabalho e a formação dos professores. Nesse sentido, Alarcão $(1996 ; 2001$; 2004) aponta que o entorno epistemológico que a formação dos professores assume na atualidade presume a transposição de uma atitude reflexiva excessivamente centrada no professor isolado e auto-suficiente para uma prática reflexiva construída no coletivo, organizando o que ela denomina de "escola reflexiva".

\footnotetext{
${ }^{2}$ Referente à obra The reflective practitioner, de 1983 (MIZUKAMI et. al., 2002).
} 
Escola reflexiva entendida como aquela que ao formar também forma a si mesma, por meio de um trabalho participativo e colaborativo.

Isso permite pensar que, assim como a escola reflexiva, uma escola com proposta inclusiva necessita se constituir em espaço de diversidade, de colaboração e trabalho em equipe, comprometida com a aprendizagem tanto discente como docente. Isso irá exigir de todos os envolvidos no processo educacional inclusivo, uma reflexão sistemática e cooperativa sobre as situações práticas vividas no contexto escolar, com vistas à melhoria do ensino desenvolvido e ao aprimoramento da instituição de modo geral.

Em uma escola aberta e democrática, todos os seus membros devem ser "[...] incentivados e mobilizados para a participação, a co-construção, o diálogo, a reflexão, a iniciativa, a experimentação" (ALARCÃO, 2001, p. 26). A escola concebida como espaço de reflexão e de inclusão, deve proporcionar as condições necessárias para que seus professores se desenvolvam profissionalmente, refletindo sobre suas práticas e sobre as próprias condições em que atuam, a fim de promover melhorias no seu ensino. Deve, igualmente, propiciar a vivência de ações reflexivas em torno das situações cotidianas, buscando soluções conjuntas para os problemas enfrentados, visando a promoção de uma formação continuada gerada a partir das próprias necessidades vivenciadas no cotidiano escolar.

Alarcão (2004) chama a atenção para o fato de que a postura reflexiva na tarefa de ensinar não se constrói de maneira espontânea, mas precisa ser desenvolvida. Para tanto, é necessário a utilização de estratégias capazes de promover a reflexão e a participação ativa do professor no seu processo formativo, favorecendo o desenvolvimento profissional e a aquisição das habilidades e competências necessárias para lidar com exigências impostas pelas reformas educacionais.

Nessa direção, casos de ensino e método de casos têm sido apontados como estratégias de promoção e investigação de processos de formação docente (SHULMAN, L., 1992; SHULMAN, J., 1992; 2000; 2002; GARCÍA, 1995; MERSETH, 1996; MIZUKAMI; 2000; NONO; 2005; entre outros), oferecendo promissoras oportunidades para a formação e para a aprendizagem docente. Os autores também situam a necessidade de realização de estudos que possam oferecer maiores esclarecimentos quanto às potencialidades e limitações dessa ferramenta de ensino e de pesquisa.

De acordo com Merseth (1996), um caso de ensino pode ser definido como um documento de pesquisa descritivo de um evento ou situação da vida real, de caráter 
multidimensional que representa o contexto, seus participantes e a realidade da situação. Shulman, L. (1992), destaca que o caso de ensino tem uma narrativa, uma história, um conjunto de eventos que transcorre em certo tempo e em local específico. Em geral, estas narrativas de ensino possuem características comuns, tais como: apresentam princípio, meio e fim e podem incluir, também, uma tensão dramática a ser aliviada; são particulares e específicas e não sentenças genéricas; situam os eventos no tempo e espaço; revelam o trabalho de mãos, mentes, motivos, concepções, necessidades, frustrações e falhas humanas; refletem o contexto sociocultural no qual o evento ocorre.

Entretanto, nem toda descrição de um evento ocorrido em sala de aula constitui um caso de ensino a priori, uma vez que estes:

Não são simplesmente histórias que qualquer pessoa possa contar. Eles são elaborados em narrativas convincentes, situados em um determinado acontecimento ou uma série deles que se revelam com o tempo. Eles têm um enredo que é focado em uma problemática com uma certa tensão que deve ser aliviada. São recheados de problemas que podem ser enquadrados e analisados a partir de várias perspectivas, e incluem os pensamentos e sentimentos dos professores ao elaborarem suas descrições. Os casos também abarcam comentários reflexivos do autor que levanta alguns questionamentos sobre o que eles podem fazer diferente no futuro (SHULMAN, J., 2002, p. 3).

Alarcão (2004), ao discutir a formação do professor em uma vertente reflexiva, afirma que em razão do caráter altamente contextualizado e complexo da atividade docente, a análise de episódios reais de ensino apresenta-se como uma estratégia de grande valor formativo, pois permite desvelar situações complexas e construir conhecimento ou tomar consciência do que, afinal, já se sabia.

Descreve, assim, que os casos de ensino

[...] são a expressão do pensamento sobre uma situação concreta que, pelo seu significado, atraiu a nossa atenção e merece a nossa reflexão. São descrições, devidamente contextualizadas, que revelam conhecimento sobre algo que, normalmente, é complexo e sujeito a interpretações. Os casos que os professores contam revelam o que eles ou os seus alunos fazem, sentem, pensam, conhecem (ALARCÃO, 2004, p. 52).

Com base nos autores supracitados, entende-se que os casos de ensino, ao envolverem a descrição de fatos ou eventos ocorridos em um contexto escolar específico e que tem o professor e seus alunos como seus reais protagonistas, representam uma estratégia profícua no sentido de oportunizar aos profissionais do ensino regular a possibilidade de refletir sobre a sua ação, individual e coletivamente. A experiência do professor, nessa perspectiva, assume lugar de destaque na aprendizagem profissional da docência. Trata-se de 
aprender na prática e pela prática, mobilizando e construindo novos saberes que servirão de base para o exercício da docência.

Merseth (1996) distingue três diferentes propósitos que orientam a utilização de casos de ensino na formação docente. Segundo a autora, os casos podem ser usados como exemplos; como oportunidades para praticar a tomada de decisões e resolução de problemas práticos; e como estímulo pessoal à reflexão. Casos usados como exemplos enfatizam a teoria e priorizam o conhecimento proposicional; seu objetivo é desenvolver o conhecimento de uma teoria ou a construção de novas teorias. Como oportunidade para praticar a tomada de decisões, os casos podem ajudar os professores a 'pensar como professores' pela apresentação de situações escolares das quais a teoria emerge; trazem situações problemáticas que requerem identificação e análise do problema, tomada de decisão e definição da ação. Finalmente, o caso como estímulo à reflexão enfatiza a introspecção e o desenvolvimento do conhecimento profissional; permite o desenvolvimento de hábitos e técnicas de reflexão.

Reforçando tais aspectos, Nono (2005) afirma que os casos de ensino são ferramentas capazes de possibilitar o estabelecimento de relações entre questões educacionais mais amplas e contextos educacionais mais específicos e de familiarizar o professor em formação e em exercício com processos de reflexão em torno de suas práticas e de outros profissionais, como possibilidades de aprendizagem pela experiência.

Em síntese, os casos de ensino caracterizam-se como narrativas que mostram situações complexas vividas por professores durante sua atividade docente. Trazem exemplos de como lidar com determinadas situações e, mais que isso, explicitam dilemas e conflitos enfrentados por docentes ao lidar com o ensino e com seus alunos. Mostram como determinada aula foi conduzida e quais problemas surgiram no decorrer das atividades. Trazem situações parecidas, enfrentadas por diversos professores em diferentes situações escolares, servindo de estímulo à reflexão e de exemplo para que outros professores possam se inspirar, pensando estratégias de como conduzir as atividades em sala de aula.

Em sua pesquisa, Nono (2005) elaborou um esquema constituído por quatro dimensões para análise dos processos reflexivos evidenciados por professoras iniciantes, mediante a estratégia de casos de ensino. A primeira dimensão do processo reflexivo se refere à capacidade das professoras em descrever/explicitar suas próprias ações em sala de aula. A segunda dimensão compreende a capacidade das professoras descreverem/explicitarem teorias pessoais, assim como conhecimentos e crenças que orientam suas ações. Na terceira 
dimensão as professoras procuram examinar suas formas de atuação e os conhecimentos que as fundamentam. Tal processo pode compreender a busca das fontes de constituição desses conhecimentos e ações, a tentativa de estabelecer relações entre suas práticas e as teorias pessoais que as informam, a comparação entre seus modos de atuação em diferentes momentos da carreira e perante as diferentes solicitações da prática, a busca por justificativas diversas para seu desempenho profissional, o estabelecimento de relações entre aspectos práticos e teóricos do ensino, análise dos efeitos de sua atuação sobre os demais sujeitos envolvidos no ato pedagógico, bem como a influência das ações dos outros sobre a própria atuação. Por fim, a quarta dimensão envolve uma revisão das ações e conhecimentos profissionais, incluindo a compreensão dos fatores que levaram ao redimensionamento da atuação, ou, ainda, a manutenção de suas formas de agir e de seus conhecimentos, aliada a uma maior possibilidade de entendimento sobre eles.

No tocante à inclusão escolar, acredita-se que os casos de ensino representam uma possibilidade de mobilizar atos reflexivos nos professores, na medida em que abordam situações de ensino vivenciadas no cotidiano escolar, relatadas por outros profissionais ou pelos próprios professores envolvidos na ação formativa, permitindo discutir temáticas diversas, englobando as diferentes dimensões da docência: pedagógica, técnica, teórica, política e social. Ademais, permitem ao docente o afastamento necessário à reflexão da sua ação, potencializando as chances de efetivar as mudanças necessárias em seu ensino.

\section{ASPECTOS METODOLÓGICOS DA PESQUISA}

Participaram da pesquisa oito docentes do ensino fundamental de uma escola da rede pública municipal de Nata1/RN/Brasil. Inicialmente, foi entregue uma Carta-Convite e um Termo de Consentimento Livre e Esclarecido às professoras da escola, a fim de informá-las sobre os objetivos da pesquisa, confirmar o interesse em participar e solicitar a autorização para a realização do estudo. Por questões éticas da pesquisa, os nomes utilizados ao longo deste artigo são fictícios.

Metodologicamente, optou-se pelo modelo construtivo-colaborativo de pesquisaintervenção (COLE; KNOWLES, 1993) que, de modo geral, possibilita investigar os professores e suas práticas pedagógicas no intuito de compreender a realidade escolar, assim como a singularidade dos sujeitos que fazem parte deste contexto. Esse modelo prevê o 
estabelecimento de uma relação de parceria entre pesquisador e professores, levando a aprendizagens mútuas.

Para o desenvolvimento da pesquisa foram utilizados os casos de ensino. Conforme explicitado anteriormente, a opção por esta estratégia específica se deu pelo seu potencial formativo e investigativo que permite ao professor, auxiliado pelo pesquisador, expor aspectos relativos à sua prática pedagógica, analisando, indagando e refletindo sobre a própria experiência e de outros profissionais, vivenciada em contexto específico.

A utilização dos casos de ensino ocorreu sob duas perspectivas: análise individual e coletiva de casos já existentes na literatura; elaboração de um caso de ensino pelas professoras participantes, seguida de sua discussão na coletividade docente.

Inicialmente, foram analisados quatro casos de ensino ${ }^{3}$ com temáticas diversas relacionadas à inclusão escolar: dificuldades enfrentadas, dilemas profissionais, intervenção pedagógica, adaptações curriculares, interação professor-aluno/aluno-aluno, estratégias de ensino, avaliação da aprendizagem, formação de professores, entre outras. Cada caso foi seguido de um roteiro de questões abertas para serem respondidas individualmente e, posteriormente, discutidas no grupo. O prazo para análise de cada caso foi de, aproximadamente, 20 dias. Entre a análise de um caso e outro, eram realizados os encontros para discussão coletiva, com duração de 1 hora e 30 minutos.

Concluída esta fase, cada professor elaborou um caso de ensino individualmente a partir de suas experiências com alunos com deficiência na sala de aula regular. Para tanto, foi entregue um roteiro com algumas orientações, tais como: explicitar a temática do caso, compor uma história com começo, meio e fim, procurando não emitir julgamentos no texto, além de situar o contexto, os alunos, os materiais utilizados, as atividades desenvolvidas, entre outros. Ao concluir o caso, foi solicitado que explicitassem os motivos da escolha daquela situação específica, listando as aprendizagens ocorridas a partir do relato. As produções também foram compartilhadas e analisadas coletivamente.

Quanto ao grupo participante da pesquisa, este foi composto por oito professoras dos anos iniciais do Ensino Fundamental, as quais se envolveram em todas as fases do estudo: análise, elaboração e discussão de casos de ensino. Em comum, as professoras têm a atuação profissional na rede pública e na particular na cidade de Natal/RN. Todas possuem formação

\footnotetext{
${ }^{3} \mathrm{C} 1$ - Trajetória profissional de Adriana: o desafio de desenvolver uma prática inclusiva; C2 - E agora? O que vou fazer?; C3 - Do conhecimento do aluno à sua inclusão; C4 - Relatando um caso de inclusão no ensino regular; CE - Caso Elaborado.
} 
em nível superior em áreas diversas: Pedagogia, Educação Física, Artes e Letras. Flora (55 anos) é graduada em Pedagogia, assim como Sônia (43 anos), Ana (33 anos), Célia (39 anos) e Clara (35 anos). Dalva (53 anos) é formada em Artes. Aline (29 anos), em Educação Física, e Liana (59 anos) é formada em Letras. Os anos de conclusão datam entre 1976 e 2003. Apesar desse longo período, um ponto em comum nos discursos das profissionais refere-se à ausência de informações e/ou à formação insuficiente para lidar com a inclusão de alunos com deficiência no ensino regular. Somente a professora Ana mencionou ter uma disciplina denominada "Introdução à Educação Especial" em sua formação, a qual foi considerada por ela como inadequada, devido à distância da realidade escolar.

Quanto ao tempo de experiência profissional, Flora, Célia, Dalva e Liana exercem a profissão há mais de 20 anos. Sônia atua há mais de 15 anos. Ana, Clara e Aline lecionam há aproximadamente cinco anos. No tocante à atuação com alunos com deficiência, destaca-se que todas as professoras já tiveram experiência anterior e/ou estavam atuando com os mesmos no período em que a pesquisa foi realizada.

Para fins de análise dos processos reflexivos explicitados pelas participantes da pesquisa, foi considerada a categorização proposta por Nono (2005), ao definir que a reflexão pode ocorrer em quatro dimensões distintas, porém contínuas e interdependentes. A partir da elaboração dos casos de ensino, foram selecionados trechos que permitem visualizar tais processos, vividos pelas professoras do estudo, focalizando possíveis contribuições desta estratégia para os processos de formação e reflexão docente.

\section{ELABORAÇÃO DE CASOS DE ENSINO E PROCESSOS REFLEXIVOS DE PROFESSORAS QUE ATUAM NA ESCOLA INCLUSIVA}

Ao produzirem um caso de ensino, as professoras descrevem conteúdos que ensinaram ou tentaram ensinar aos seus alunos, objetivos que orientaram suas práticas e tomadas de decisão na classe, as relações estabelecidas com os alunos, os recursos materiais e as estratégias de ensino que selecionaram para o desenvolvimento das aulas, bem como as formas de avaliação empregadas. Logo, é possível afirmar que estas profissionais se envolveram em uma primeira dimensão da reflexão docente, ainda que o façam sob diferentes matizes e com níveis distintos de aprofundamento e detalhamento dos episódios descritos.

Contudo, é preciso destacar que o processo de elaboração dos casos não foi livre de impasses e dificuldades. Enquanto algumas professoras mostravam disposição para relatar 
aspectos da sua prática pedagógica junto a alunos com deficiência, outras apresentavam uma postura reticente, indicativa do receio de se expor e serem julgadas por isso. Esta parece ter sido a situação de Sônia, professora de Jéssica, aluna com Síndrome de Asperger. Tal aspecto parece justificar o fato de que no dia reservado à socialização e discussão dos casos elaborados, a professora optou por relatar uma situação de ensino vivenciada em outro momento da sua carreira profissional: "No caso, eu tenho também a questão da Jéssica que está me angustiando bastante, mas não foi a que eu resolvi relatar". Quando questionada, em um momento posterior, sobre os motivos da sua escolha, ela respondeu: "[...] não escrevi sobre a Jéssica porque ia mexer com muita coisa e alguém poderia não gostar”. Mas no decorrer da pesquisa-intervenção a professora se mostrou disposta e confiante para escrever sobre a experiência vivida com Jéssica, que tanta angústia lhe causava. Fato semelhante ocorreu com a professora Clara ao dizer que não pretendia relatar uma situação envolvendo Luís, aluno com paralisia cerebral, “[...] porque eu não fico muito entusiasmada em escrever sobre essa situação"; e com a professora Dalva que, inicialmente, afirmou não ter interesse em elaborar o seu próprio caso "[...] não, eu não vou relatar esse caso”.

Outras professoras, ainda que não tenham verbalizado desta forma, também davam indícios de sua resistência em escrever. A falta de tempo e a própria dificuldade em selecionar um episódio que pudesse ser transformado em um caso de ensino foram pontuadas pelas professoras. Justificavam, em geral, que não viam como a sua experiência poderia auxiliar outros profissionais a lidarem com a inclusão escolar. Oscilavam entre o medo de se expor e o desejo de compartilhar e refletir sobre as práticas desenvolvidas na escola, aprendendo com a própria experiência e a das colegas.

A resistência evidenciada pelas professoras guarda relação, dentre outros aspectos, com o fato de que o exercício de reflexão, individual e/ou coletivo, sobre uma situação específica de ensino e escrever sobre ela não é um processo comum aos profissionais da área educacional. Com efeito, a opção pela elaboração do seu próprio caso de ensino representa um ganho e aponta para a disposição dessas professoras de refletir sobre a própria prática e sobre o processo educacional inclusivo, visando romper com aquilo que suscita resistência (JESUS, 2003).

Richert (1992) também constatou a resistência de muitos professores em escrever sobre o seu trabalho. Essa resistência, segundo ele, está atrelada à ideia de que a docência é uma profissão do "fazer" e não do "escrever". É fato que os professores dispõem de pouco 
tempo/oportunidade para falar sobre o que sabem e, muito menos, para escrever sobre isto. Deste modo, os casos escritos, bem como a redação de casos, oferecem uma oportunidade para ser criado um registro do que os professores sabem sobre seu trabalho e como eles sabem disso. Oferecer momentos para que os professores possam escrever sobre suas experiências pedagógicas pode contribuir para minimizar tais resistências, tornando essa tarefa mais fácil e melhor compreendida pelos docentes. Os trechos a seguir ilustram como a elaboração de casos auxiliou este processo:

Logo de início resisti, não queria escrever sobre essa experiência por considerá-la mal sucedida. Mudei de ideia ao perceber o significado dessa situação para meu processo de aprendizagem profissional e por ter me chamado a atenção para a questão da inclusão, pois até agora, não havia parado para pensar nisso (Clara).

Escolhi esta situação para comentar porque eu consegui êxito dentro da realidade da Maria, consegui ver frutos. [...] Eu quis fazer um registro de sucesso e não apenas de angústia e frustração que é o mais comum (Aline).

Ao escrever esse caso, fiz o que nunca tinha parado para fazer: analisando para descrever situações (Liana).

Por meio da elaboração dos casos de ensino, as professoras parecem ter alcançado uma segunda dimensão dos processos de reflexão, ao apontarem conhecimentos, crenças, valores e concepções que orientam sua ação pedagógica. De acordo com Richard (1995), os conhecimentos e as crenças que os docentes possuem acabam por guiar suas ações. Esse autor também argumenta que as expectativas do professor em relação a um aluno em particular ou em relação à turma toda afetam, substancialmente, o estilo de interação e de relação estabelecida entre ele e seus alunos e, em alguns casos, o que os alunos aprendem.

Nesse sentido, aspectos comuns marcam os relatos do grupo participante desta investigação. De modo geral, essas professoras destacam suas crenças e concepções relativas, especialmente, às características dos alunos com deficiência, às limitações e dificuldades destes em aprender como uma forma de justificar suas (não) ações em sala de aula. Por outro lado, enquanto algumas afirmam que para incluir não há receita, existem aquelas que insistem na ideia de uma preparação prévia para ensinar esses alunos, como condição essencial para que a inclusão se efetive nas escolas.

Tais crenças e concepções influenciam a ação pedagógica das professoras, ao entrarem em contato com a diferença destes educandos. Suas reações indicam que vislumbram desde uma verdadeira possibilidade de crescimento, aprendizagem e aprimoramento pessoal e profissional até um verdadeiro empecilho ao desenvolvimento da 
sua prática. Nota-se, assim, que enquanto algumas conseguem reverter esse quadro, outras permanecem mergulhadas em um mar de descrença e impossibilidades.

Até então tinha um entendimento errôneo e preconceituoso de que a criança com deficiência não conseguiria aprender. Ao me deparar com essa experiência fui obrigada a mudar minhas atitudes, passando a diversificar as aulas, mudando a forma de planejar e avaliar (Flora).

[...] embora ele estivesse em sala de aula, acreditava que não teria muito progresso. Também não me sentia responsável pelo fato dele não estar aprendendo, de não conseguir fazer as atividades, e atribuía isso às suas limitações. Acreditava que a socialização, a convivência com os outros alunos já representava um avanço (Clara).

Uma terceira dimensão dos processos reflexivos foi alcançada pelas professoras, ao expressarem mudanças nas formas de conceber e de atuar frente ao aluno com deficiência. Demonstraram, portanto, disposição para refletir sobre a sua prática, sobre o seu contexto de trabalho e sobre os alunos, com a intenção de reorientar as suas ações, a fim de garantir a aprendizagem de todos.

A escrita dos casos surgiu como uma possibilidade de sistematização de suas práticas, suscitando dúvidas e questionamentos sobre o trabalho desenvolvido. Isso sugere, de um lado, o compromisso dessas professoras para com o seu ensino e, apesar das adversidades que caracterizam o seu cotidiano profissional, mostram-se capazes de tomar decisões, fazendo opções teórico-metodológicas, de modo a adequar o seu ensino ao público por elas atendido. De outro, porém, nota-se que a revisão da própria atuação surge como um processo doloroso e difícil de ser concretizado para algumas dessas profissionais, pois se sentem incapazes de atuar na perspectiva de ensinar a todos e apresentam dificuldade em romper com determinados conhecimentos e práticas que compõe o seu repertório pedagógico.

Fico muito frustrada e angustiada quando vejo Luís na sala de aula, pois percebo o seu desejo em envolver-se e participar das atividades. Mas, sinceramente, não sei se isso é possível (Dalva).

Atitudes como esta, acarretaram, por vezes, uma postura pouco crítica quanto às possibilidades de intervenção dessas professoras, supervalorizando as dificuldades e as limitações dos alunos e do próprio contexto escolar em que estão inseridas, como obstáculos à sua atuação pedagógica. Indícios de revisão das próprias posturas profissionais puderam ser evidenciadas a partir da socialização e discussão dos casos elaborados. O tempo para reflexão coletiva parece ter atuado como condição para estimular o desejo de mudança, na medida em que o grupo era convocado a rever atitudes e práticas e, com isso, o seu papel no processo inclusivo. 
Com Luís aprendi que, às vezes, para se ver bem, é preciso mudar o foco do nosso olhar. Foi assim que, revendo o papel do aluno, pude rever meu próprio papel como profissional, e a responsabilidade que me cabe no processo de ensino-aprendizagem. Passei de uma visão do aluno como o único responsável e que precisa se adequar à escola para outra, em que a escola e seus profissionais precisam oferecer condições para que todos aprendam (Clara).

Esta experiência serviu para reafirmar a minha convicção de que o conhecimento não tem limite, nem para mim, nem para meus alunos, que cada um é único e, ao professor, cabe a importante tarefa de buscar superar as próprias limitações a fim de contribuir significativamente para que cada um possa ter acesso ao saber. A verdade é que ninguém está preparado para incluir esses alunos, ninguém tem essa receita, mas temos o dever de tentar (Ana).

Aprendi que cada pessoa além de ser um desafio, nos ensina, nos faz crescer. Só lidando com Isadora, vi o quanto cresci, o quanto me abri para aprender (Liana).

As professoras também evidenciaram capacidade de avaliação e de revisão do ensino que desenvolvem, bem como dos conhecimentos profissionais que possuem, com indícios de mudanças em suas formas de pensar e agir, avançando em direção ao alcance da quarta dimensão dos processos reflexivos. Os episódios descritos indicam a complexidade que marca a sala de aula devido à multiplicidade, simultaneidade e imprevisibilidade de situações com as quais as professoras precisam lidar quase sempre de forma imediata, tendo, em geral, pouco tempo para refletir sobre elas.

De acordo com Mizukami (2000, p. 143):

Professores lidam diariamente com situações complexas e, considerando o ritmo acelerado das atividades e as múltiplas variáveis em interação, há pouca oportunidade para que possam refletir sobre os problemas e para que possam trazer seus conhecimentos à tona para analisá-los e interpretá-los.

Verificou-se, assim, que a reflexão distanciada do momento da ação, possibilitou às professoras realizar uma releitura de suas práticas, ressignificando a experiência vivida. Nesse exercício, muitas vezes, as professoras tiveram suas certezas abaladas, com lugar para dúvidas e indagações sobre o próprio ensino, em que pese a necessidade de mudanças com vistas ao desenvolvimento de uma prática de ensino pautada nos princípios inclusivos.

Ao lançarem um olhar mais atento sobre suas formas de atuar e pensar o seu ensino, elas passaram a conceber novas hipóteses sobre como intervir pedagogicamente em turmas com alunos com deficiência, construindo e reconstruindo seus conhecimentos profissionais. Esse aspecto é de suma relevância para o contexto da Educação Inclusiva, pois viabiliza a revisão das estratégias de intervenção empregadas pelos professores e a influência destas sobre a aprendizagem do aluno. Ademais, permite ao professor assumir novas posturas, responsabilizando-se pela aprendizagem de todos os educandos. Ou seja: "A releitura da situação pode favorecer uma mudança de atitude, uma reorganização de procedimentos, a 
percepção de possíveis contradições entre o que fez e o que poderia ter sido feito, ou ainda, a intencionalidade da situação exitosa" (SADALLA, 2006, p. 03).

Muito embora nem todas as professoras tenham alcançado essa dimensão da reflexividade docente ao elaborarem seu caso de ensino, um ponto forte da ação proposta refere-se à possibilidade das professoras compartilharem suas produções no grupo. Ao refletirem coletivamente sobre as situações vividas no cotidiano da prática pedagógica e os dilemas que enfrentam no trabalho junto a alunos com deficiência, essas professoras foram capazes de identificar e avaliar estratégias de intervenção por elas empregadas, buscando soluções para os problemas que enfrentam.

Isso sugere, a exemplo do que constatou Nono (2005), a necessidade dos professores terem mais oportunidades de descrever e analisar suas formas de atuação, retomando a escrita do próprio caso. Isso também aponta para a importância de se estabelecer momentos de diálogo entre os diversos atores da ação formativa, favorecendo o desenvolvimento de uma atitude crítica e investigativa sobre o próprio ensino que desenvolvem, com possibilidades de mudanças.

Uma vez pontuadas as dificuldades vividas em cada caso e discutidas as possibilidades de intervenção visando atender aos princípios inclusivos, as participantes da pesquisa, em um processo de reflexão coletivo e colaborativo, listaram uma série de aspectos considerados essenciais para que a escola em que atuam se torne, de fato, inclusiva.

Trata-se de sugestões que extrapolam o âmbito da sala de aula e da ação isolada do professor, as quais poderiam ser categorizadas sob três eixos principais: atitudinal, pedagógico, organizacional. No âmbito atitudinal, a ênfase recai sobre a necessidade da escola, como instituição, assumir o compromisso com a aprendizagem de todos os alunos; do professor estar sempre disposto/aberto à mudança; de ser sensível e acolher as diferenças trabalhando a solidariedade e o respeito; de buscar ajuda junto a outros profissionais dentro e fora da escola. No âmbito pedagógico, ou seja, de sala de aula, as professoras destacam a importância de trabalhar com os pares, de adaptar atividades e materiais pedagógicos de acordo com a condição do aluno, empregar a metodologia de projetos, oferecer atendimento individualizado em sala de aula, além de sequenciar conteúdos extensos. Já no âmbito organizacional, pontuam a necessidade de contar com profissional de apoio dentro e fora da sala de aula; participação em cursos de formação de forma periódica; momentos para troca de 
experiências na escola; estabelecer parcerias com escolas especiais; promover encontros com a família para sensibilização e conscientização sobre as condições dos alunos.

Nessa direção, vale retomar os momentos de discussão coletiva dos casos estudados e elaborados como um ponto forte do trabalho desenvolvido. Os dados demonstraram que, por meio das discussões coletivas, aspectos focalizados individualmente puderam ser analisados mais profundamente no grupo, uma vez que diferentes ideias, opiniões e entendimentos acerca de uma mesma situação descrita puderam ser socializados, analisados e confrontados. Isso comprova o já exposto por Levin (1999) em relação à discussão em pequenos ou grandes grupos como uma variável crucial do aprendizado por casos, uma vez que os participantes dessas discussões são influenciados por outros indivíduos do grupo, gerando um repensar das suas próprias compreensões sobre as questões abordadas no caso.

Isso corrobora a importância de se criar, nas escolas, uma cultura de registro e análise das suas práticas, resultando num conjunto consistente de casos de ensino construídos por professores, para que possam ser acessados pelos docentes quando desejarem ter ideias/exemplos sobre como ensinar determinado conteúdo aos seus alunos e/ou como lidar com situações conflitantes (NONO, 2005).

Para ilustrar o acima exposto, são apresentadas algumas falas, representativas das opiniões das professoras participantes desta pesquisa-intervenção acerca da relevância da estratégia de elaboração e discussão de casos para seus processos de aprendizagem da docência e para despertá-las para a importância do seu papel frente à inclusão:

Eu acho que apesar de ser nova, a metodologia foi boa porque a gente passou a pensar em casos reais que aconteceram, e a partir desses casos reais passamos a pensar na nossa escola, casos que a gente tem aqui, ou casos que a gente já vivenciou [...]. Para além do envolvimento para refletir, escrever, o mais importante pode ter sido essa "mexida" que você [referindo-se à pesquisadora] pode ter provocado em nós (Ana).

Aprendi muito com a troca de experiências, os casos estudados, foi uma formação continuada voltada para a inclusão de uma forma muito diferenciada, diferente das tantas que eu já participei e acredito que deixou um grande aprendizado para todos nós (Flora).

E outra coisa, [...] que é a dificuldade de conseguir colocar, relatar casos como se a gente nunca tivesse vivido, e vivemos tantos, [...], eu quero ter um registro, a partir de agora [...] Então, eu quero fazer esse registro, eu quero pra mim isso, até pra eu me avaliar, pra ver desse tempo pra cá, o que vem mudando, acho que a ideia era essa que a gente refletisse e procurasse melhorar e eu acho que valeu, e muito! (Sônia).

Aprendi que é preciso refletir, pensar e registrar nossas experiências, para apoiar o pensamento, propor ideias e resgatá-las (Célia). 
Nesta perspectiva, reafirma-se a necessidade de disponibilizar espaços que proporcionem o encontro entre os profissionais que trabalham nas escolas, para que possam compartilhar experiências e refletir sobre suas práticas, em prol da elaboração de estratégias de enfrentamento para as situações vivenciadas no ambiente escolar. Com efeito, os casos de ensino, ao retratarem experiências vividas no cotidiano escolar, podem servir como um dos instrumentos capazes de viabilizar o estabelecimento de trocas e o diálogo entre os pares, confrontando ideias e práticas, e como estímulo à reflexão e tomada de decisões sobre os rumos da própria ação pedagógica.

\section{CONSIDERAÇÕES FINAIS}

O presente artigo abordou o potencial dos casos de ensino enquanto instrumento investigativo e formativo que possibilita a análise das experiências vividas no cotidiano escolar, fomentando processos reflexivos em professores sobre a prática pedagógica desenvolvida junto a alunos com deficiência no ensino regular.

De modo geral, observa-se que a elaboração de casos de ensino permitiu às professoras distanciarem-se de sua ação, favorecendo o processo reflexivo e a tomada de consciência de aspectos que precisam ser melhorados na sua prática pedagógica. A escrita de casos facilitou a sistematização de situações vividas no cotidiano da sala de aula, servindo como um dispositivo de avaliação docente, onde as professoras puderam retomar seus escritos revendo posturas, atitudes e ações junto ao aluno com deficiência.

Destaca-se, pois, o potencial formativo da estratégia de casos de ensino, permitindo às professoras do ensino regular, descrever, analisar e aprender com a sua experiência e a experiência de outras profissionais. Nesse sentido, o uso dos casos de ensino representou um momento para pensarem sobre seus modos de ensinar, favorecendo a emergência de uma postura reflexiva. São importantes ferramentas de investigação e sistematização da prática, contribuindo para a explicitação e a tomada de consciência das crenças, concepções e conhecimentos que embasam as ações docentes.

Em se tratando, especificamente, da formação continuada de professores para o ensino inclusivo, o processo de elaboração e discussão dos casos representou, no âmbito da escola investigada, um espaço de diálogo e reflexão conjunta, em que as professoras expuseram suas experiências, compartilharam sentimentos, dúvidas e inseguranças, e 
buscaram coletivamente, alternativas visando à construção de uma nova lógica de ensino que acolha a diversidade.

Conclui-se, assim, que os casos de ensino proporcionaram às professoras do estudo, oportunidades para aprender e desenvolverem-se profissionalmente, sugerindo a sua adequação como ferramenta a ser utilizada em pesquisas e em programas de formação docente, ancorados na perspectiva do professor reflexivo.

\section{REFERÊNCIAS}

ALARCÃO, I. (Org.). Reflexão crítica sobre o pensamento de D. Schön e os programas de formação de professores. In: ALARCÃO, I. (Org.). Formação reflexiva de professores: estratégias de supervisão. Porto: Porto Editora, 1996. p. 9-39. (Coleção CIDInE, 1).

ALARCÃO, I. A escola reflexiva. In: ALARCÃO, I. (Org.). Escola reflexiva e nova racionalidade. Porto Alegre: Artmed, 2001. p. 15-30.

ALARCÃO, I. Professores reflexivos em uma escola reflexiva. 3. ed. São Paulo: Cortez, 2004. (Coleção Questões da Nossa Época, 103).

ALARCÃO, I. Refletir na prática. Nova Escola, São Paulo, ano 17, n. 154, p. 45-47, ago. 2002.

COLE, A.; KNOWLES, J. Teacher development partnership research: a focus on methods and issues. American Educational Research Journal, vol. 30, n. 3, p. 473-495, 1993.

GARCÍA, C. M. A formação de professores: novas perspectivas baseadas na investigação sobre o pensamento do professor. In: NÓVOA, A. (Org.). Os professores e sua formação. Lisboa: Dom Quixote, 1995. p. 51-76.

JESUS, D. M. O estudo de caso como dispositivo para a formação continuada numa perspectiva inclusiva. Cadernos de Pesquisa em Educação PPGE-UFES, Vitória, v. 9, n. 17, p. 104-131, jan. - jun. 2003.

LEVIN, B. B. The role of the facilitator in case discussions. In: LUNDEBERG, M. A.; LEVIN, B. B.; HARRINGTON, H. L. (Ed.). Who learns what from cases and how?: The research base for teaching and learning with cases. Mahwah, New Jersey: Lawrence Erlbaum Associates, 1999. p. 101-119.

MERSETH, K. K. Cases and case methods in teacher education. In: SIKULA, J. (Ed.). Handbook of research on teacher education. New York: Macmillan, 1996. p. 722-744.

MIZUKAMI, M. G. N. Casos de ensino e aprendizagem profissional da docência. In: ABRAMOWICZ, A.; MELLO, R. R. (Org.). Educação: pesquisas e práticas. Campinas: Papirus, 2000. p. 139-161. 
MIZUKAMI, M. G. N. et al. Escola e aprendizagem da docência: processos de investigação e formação. São Carlos: EdUFSCar, 2002.

MIZUKAMI, M. G. N. Formadores de professores, conhecimentos da docência e casos de ensino. In: REALI, A. M. M. R.; MIZUKAMI, M. G. N. (Org.). Formação de professores, práticas pedagógicas e escola. São Carlos: EdUFSCar, INEP, COMPED, 2002, p. 151-174.

NONO, M. A. Casos de ensino e professoras iniciantes. 2005. $238 \mathrm{f}$. Tese (Doutorado em Educação) - Universidade Federal de São Carlos, São Carlos, 2005.

PERRENOUD, P. A prática reflexiva no ofício de professor: profissionalização e razão pedagógica. Porto Alegre: Artmed, 2002.

RICHARD, I. A. Aprender a ensinar. Lisboa: McGraw-Hill, 1995.

RICHERT, A. E. Writing cases: a vehicle for inquiry into the teaching process. In:

SHULMAN, J. H. (Ed.). Case methods in teacher education. New York: Teachers College, 1992. p. 155-174.

SADALLA, A. M. F. A. Reflexividade e formação de professores: contribuições da psicologia. In: ENCONTRO NACIONAL DE DIDÁTICA E PRÁTICA DE ENSINO, 13., 2006, Recife. Anais...Recife: UFPE, 2006. 1 CD-ROM.

SANTOS, S. A narrativa como estratégia de formação e de reflexão sobre a prática docente. Teoria e Prática da Educação, v. 11, n. 2, p. 207-217, maio/ago, 2008.

SCHÖN, D. A. Educando o profissional reflexivo: um novo design para o ensino e a aprendizagem. Porto Alegre: Artmed, 2000.

SHULMAN, J. H. Case methods as a bridge between standards and classroom practice. [S.l.]: [s.n.], 2000. Disponível em: 〈www.ericsp.org/pages/digests/shulman.pdf >. Acesso em: 17 out. 2007.

SHULMAN, J. H. Happy Accidents: cases as opportunities for teacher learning. San Francisco, CA: WestEd, 2002. Disponível em:

$<$ http://cet.usc.edu/resources/teaching learning/docs/happy accidents.pdf $>$. Acesso em: 7 ago. 2006.

SHULMAN, J. H. Teacher-written cases with commentaries: a teacher-researcher collaboration. In: SHULMAN, J. H. (Ed.). Case methods in teacher education. New York: Teachers College, 1992. p. 131-152.

SHULMAN, L. S. Toward a pedagogy of cases. In: SHULMAN, J. H. (Ed.). Case methods in teacher education. New York: Teachers College, 1992. p. 1-30.

VARGAS, G. M. S. A inclusão no ensino superior: a experiência da disciplina Prática Pedagógica - Prática de Ensino de uma turma de alunos cegos e com baixa visão. Ponto de Vista, Florianópolis, n. 8, p. 131-138, 2006. 
ZEICHNER, K. M. A formação reflexiva de Professores: ideias e práticas. Lisboa: Educa, 1993. (Coleção Educa-Professores). 